\title{
Corrosion in Crude Oil Distillation Unit Overhead: A recent Case Study
}

\author{
Ari A. Ahmed \\ Department of Chemical Engineering, Firat University, \\ Elazı $\breve{g}$, Turkey
}

\begin{abstract}
Despite all the technological advances and the control mechanisms that exist today to achieve the control of corrosion in overhead systems in atmospheric crude oil distillation units, there is still a high level of difficulty in predicting the phenomenon due to the complexity of the chemical compounds involved in the entire process. The study of this practical case aims to determine what control mechanisms should be optimized in a refinery located in the Autonomous Region of Iraqi Kurdistan to prevent corrosion phenomena's in this specific system and how it should be done to achieve these improvements. It has been suggested that the corrosion mechanisms by hydrochloric acid and by ammonium chloride have been those that have acted in the operational context of the mentioned facility. To test this hypothesis, a study of the unit's operational conditions and analytical tests were carried out on the construction material of various components and the products (sediments) found inside the tower. The results show that a lack of control in the salts and sediments content of the feed crude have caused an increase in the hydrolysis process of certain components upstream of the tower and thus the generation of acids and salts was promoted. On this basis, it is necessary to optimize the primary treatment of crude oil and update the chemical treatments and washing water systems to adapt to the new conditions of the feed of the refinery.
\end{abstract}

Index Terms-Ammonium chloride, Crude overhead, Dew point, HCl, Salt formation, Salt hydrolysis.

\section{INTRODUCTION}

The crude distillation unit (CDU) in question is going through a forced maintenance stage, due to operational and processes upsetting that do not allow obtaining the products with the required quality and quantity.

Since the beginning of 2020, the main problems in the process were thought to be associated with the efficiency and performance of the crude heater, assuming that it was plugged due to coke deposition phenomena. Due to this, the unit was put out-of-service to check for damage and perform deep cleaning on the heater tubes. This problem was fixed

ARO-The Scientific Journal of Koya University Vol. IX, No.1 (2021), Article ID: ARO.10711, 7 pages DOI:10.14500/aro.10711

Received: 06 August 2020; Accepted: 09 February 2021

Regular research paper: Published: 01 March 2021

Corresponding author's e-mail: ari.ahmed@erbilrefinery.com Copyright (C) 2021 Ari A. Ahmed. This is an open-access article distributed under the Creative Commons Attribution License. and now it has moved to the atmospheric tower, where it has been observed that there is no outlet for Kerosene and Diesel products. In addition, there were problems in maintaining the profile of the tower, which is why it was decided to put the unit out-of-service to verify, now in greater depth, the problems in the aforementioned tower.

\section{BACKGROUND}

\section{A. Corrosion in Crude Distillation Overhead Systems}

Corrosion in crude distillation overhead systems is a common problem in refineries. According to The National Association for Corrosion Engineers International Publication 34109, the primary mechanism of concern in the overhead system is the acidic attack of unit metallurgy due to the presence of high concentrations of $\mathrm{HCl}$ in condensing water. Under-deposit corrosion and fouling usually resulting from unintended consequences of acid neutralization and/or inefficient desalter operations are also a big problem (Chambers et al., 2011, Duggan and Rechtien, 1998, Eaton et al., 2009).

Crude oils contain varying amounts of chloride salts $\left(\mathrm{NaCl}, \mathrm{MgCl}_{2}\right.$, and $\left.\mathrm{CaCl}_{2}\right)$, and these salts generally account for the bulk of the $\mathrm{HCl}$ formation and corrosion in CDUs, specifically in the overhead system.

The $\mathrm{HCl}$ is evolved from the hydrolysis of $\mathrm{MgCl}_{2}$ and $\mathrm{CaCl}_{2}$ to form $\mathrm{HCl}$ during heating in the crude oil preheat train and associated heaters. $\mathrm{NaCl}$ does not hydrolyze to a great extent under normal CDU furnace conditions. Therefore, $\mathrm{NaCl}$ generally is not considered a significant contributor to CDU distillation tower overhead system corrosion. Table I shows the hydrolysis reactions involved in this context.

Studies made by Schempp et al., Thornthwaite, et al., and Braden et al., confirm that $\mathrm{HCl}$ does not cause corrosion problems at temperatures above the aqueous dew point. However, at temperatures equal to or below the aqueous dew point, $\mathrm{HCl}$ readily dissolves in water to form corrosive hydrochloric acid. At temperatures above the aqueous dew point, $\mathrm{HCl}$ can react with some alkaline species to form corrosive salts.

$\mathrm{HCl}$, formed in the process as previously described, often combines with $\mathrm{NH}_{3}$ to form solid $\mathrm{NH}_{4} \mathrm{Cl}$ salt in $\mathrm{CDU}$ distillation tower overhead systems (Saab et al., 2005). The temperature at which $\mathrm{NH}_{4} \mathrm{Cl}$ forms is dependent on the partial pressures of $\mathrm{HCl}$ and $\mathrm{NH}_{3}$. These partial pressures can be estimated from the chloride and $\mathrm{NH}_{3}$ contents measured in 
the water phase of the associated overhead drum, accounting for the presence of water and hydrocarbon vapors in the system. Fig. 1 (Fan et al., 2001) shows the graphs normally used for this purpose.

According to Lordo (2006), $\mathrm{NH}_{3}$ may be carried into the CDU from multiple sources including the presence of $\mathrm{NH}_{3}$ in desalter wash water or from the use of $\mathrm{NH}_{3}$ as a neutralizer. Fig. 2 presents a diagram of $\mathrm{NH}_{4} \mathrm{Cl}$ salt formation at various temperatures and concentrations of $\mathrm{NH}_{3}$ and $\mathrm{HCl}$ in an overhead system. The knowledge of the salt formation

TABLE I

Hydrolysis REACTIONS

\begin{tabular}{lcc}
\hline \hline Reaction & $\begin{array}{c}\text { Approximate } \\
\text { starting temperature, } \\
{ }^{\circ} \mathrm{C}\left({ }^{\circ} \mathrm{F}\right)\end{array}$ & $\begin{array}{c}\text { Approximate degree } \\
\text { of hydrolysis at } \\
340^{\circ} \mathrm{C}\left(650^{\circ} \mathrm{F}\right)\end{array}$ \\
\hline $\mathrm{MgCl}_{2}+2 \mathrm{H}_{2} \mathrm{O} \rightarrow \mathrm{Mg}(\mathrm{OH})_{2}+2 \mathrm{HCl}$ & $120(248)$ & $90 \%$ \\
$\mathrm{CaCl}_{2}+\mathrm{H}_{2} \mathrm{O} \rightarrow \mathrm{Ca}(\mathrm{OH})_{2}+2 \mathrm{HCl}$ & $210(410)$ & $10 \%$ \\
$\mathrm{NaCl}+\mathrm{H}_{2} \mathrm{O} \rightarrow \mathrm{NaOH}+\mathrm{HCl}$ & $>500(>930)$ & $2 \%$ \\
\hline \hline
\end{tabular}

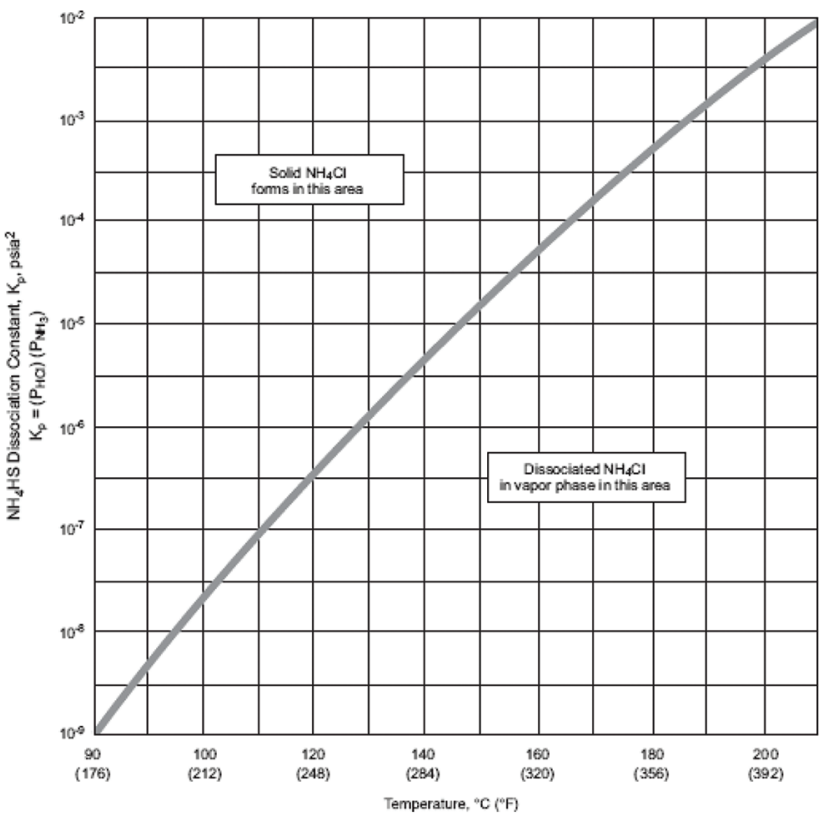

Fig. 1. $\mathrm{NH}_{4} \mathrm{Cl}$ deposition temperature estimation (Turner et al., 1998).

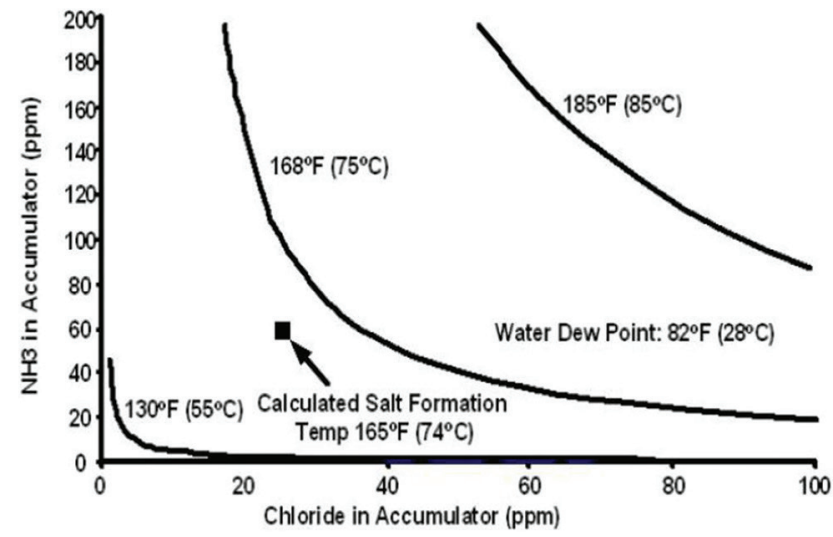

Fig. 2. $\mathrm{NH}_{4} \mathrm{Cl}$ salt formation at various overhead temperatures (Lordo et al., 2006). thermodynamics, as stated by Duggan et al., (1998) allows the construction of a figure for injection rates of neutralizer to avoid salt formation, as shown in Fig. 3.

The partial pressure of each component, that is, can be calculated by taking the moles of the component in the vapor phase divided by the total moles in the vapor phase multiplied by the absolute pressure $(\mathrm{P})$ in the process.

$\mathrm{Ppi}=($ ni vapor phase $) /($ ntotal vapor phase $) \times \mathrm{P}$

Where ni, is the mole fraction (in the vapor) of the component.

The same procedure can be used to estimate the $\mathrm{NH}_{4} \mathrm{Cl}$ deposition temperature from Fig. 1.

The net $\mathrm{NH}_{3}$ yield can be calculated from the nitrogen level in the feed and the percent denitrification.

Giesbrecht, et al., and Gutzeit, in their studies, established that the control of $\mathrm{NH}_{4} \mathrm{Cl}$ corrosion is generally approached in one of three ways. The first is lowering the formation temperature of the salt by reducing the $\mathrm{HCl}$ and $\mathrm{NH}_{3}$ contents in the overhead system. These reductions are often achieved by improving desalter operation to reduce chloride and $\mathrm{NH}_{3}$ carry-over or by eliminating external sources of $\mathrm{NH}_{3}$. Once $\mathrm{NH}_{4} \mathrm{Cl}$ is formed, corrosion is commonly controlled using continuous or intermittent water wash that is adequately distributed. Excess water is normally added to ensure that all the water is not evaporated. A common range of excess water is between 10 and $25 \mathrm{vol} \%$. This is the amount of water that is required to saturate the overhead vapor. Second, changing operations to maintain equipment temperatures above the salt formation temperature are sometimes feasible. Finally, for systems using $\mathrm{NH}_{3}$ as a neutralizer, limiting the amount of $\mathrm{NH}_{3}$ added to that required for $\mathrm{pH}$ control of the accumulated water in the overhead drum is commonly practiced.

\section{B. Process Description of the Unit Under Study}

The distillation unit has a standard configuration without facilities for crude desalination. Fig. 4 shows a simplified schematic of the unit. The crude desalter is the main defense against the presence of excessive amounts of inorganic chloride salts. The limitation of inorganic chloride salts entering the CDU substantially reduces the presence of $\mathrm{HCl}$ in the CDU overhead circuit. Experience shows that chloride content of the desalted crude feed to the CDU that exceeds 20 ppm have the potential of leading to significant corrosion and fouling problems in the overhead circuit.

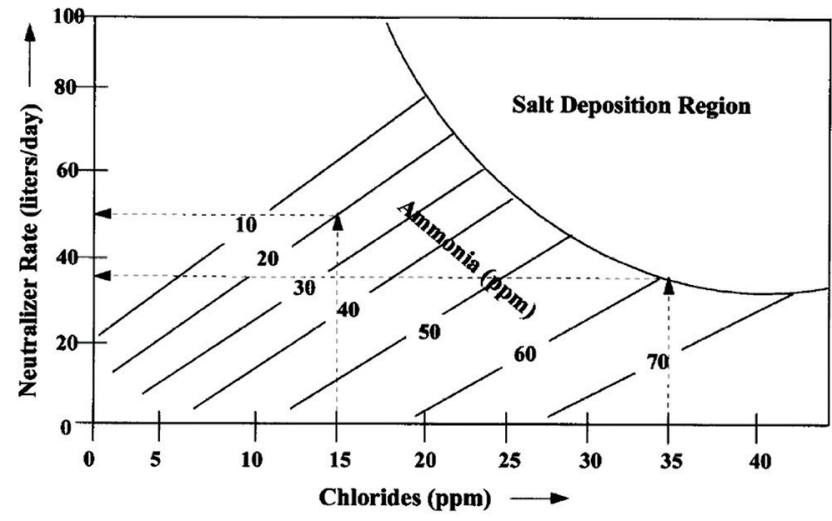

Fig. 3. Neutralizer monographs (Duggan et al., 1998). 


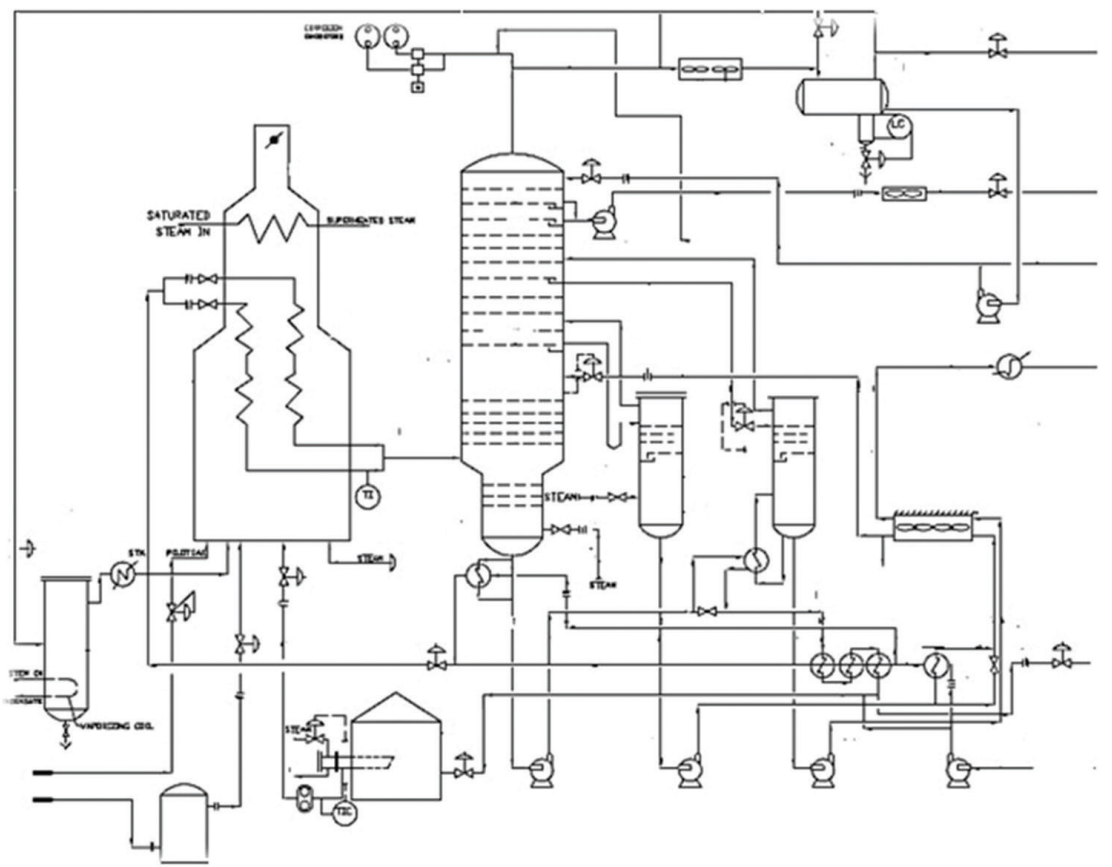

Fig. 4. Simplified scheme of the distillation unit under study (modified figure).

Crude oil feed is received from the crude feed pump and sent through a series of heat exchangers to a temperature around $162^{\circ} \mathrm{C}$. The crude oil is heated at $370^{\circ} \mathrm{C}$ in crude heater and enters atmospheric tower where it is fractionated into the following products:

- Off gas

- Light naphtha

- Heavy naphtha

- Kerosene

- Diesel

- Atmospheric residue or tower bottoms (ATB or residual fuel oil).

The overhead vapor is condensed by an air cooler and the off gas is either routed to the heater as fuel gas or to the flare depending on pressure in the overhead accumulator drum. Naphtha collects in the drum and part is pumped back to the tower as reflux and the other part pumped normally to further processing or alternately to storage.

Unstripped kerosene and diesel products are drawn from the crude tower and fed to the top of the side steam stripper. Steam stripped vapors are returned to the crude tower above the draw tray. The stripped kerosene and diesel are pumped through rundown coolers to the kerosene treater unit provided by others and storage.

Below the flash zone the residue is steam stripped inside the crude column to reduce the volatiles. The atmospheric tower bottoms product is fuel oil and is cooled by heat exchange with the crude rundown to storage.

\section{CASE STUdy}

Fig. 5 shows a simple schematic of the tower. It is an equipment manufactured basically in Monel (alloy 400),

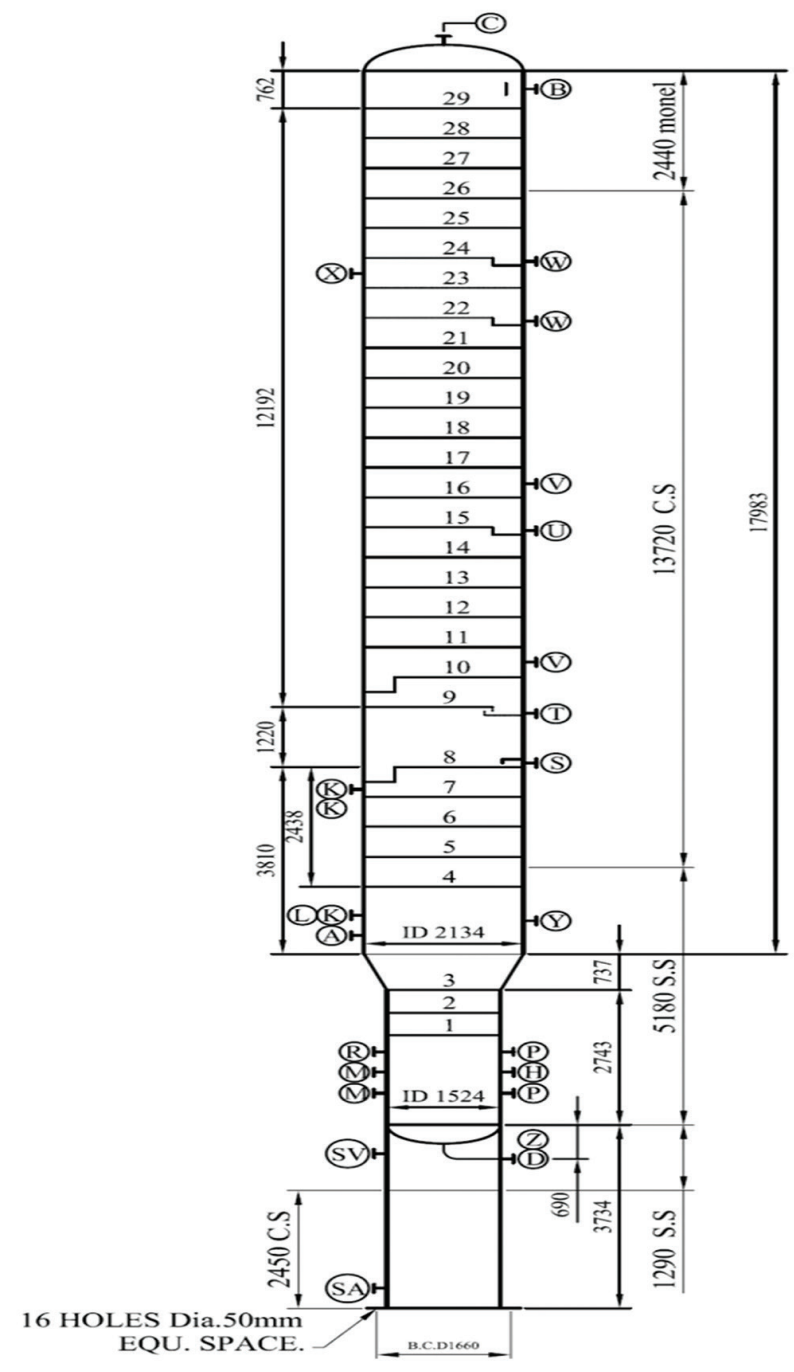

Fig. 5. V-111 simplified scheme. 
carbon steel and martensitic stainless steel. The solid Monel is above the tray 25, between tray 5 and 25 is carbon steel and below tray 5 there is SS410.

The tower has a 20-inch manhole for the entry and removal of trays; these are attached to the tower with support rings. Its diameter is $21634 \mathrm{~mm}$, except for the three first trays, which have $1524 \mathrm{~mm}$ in diameter. The flow control mechanism is through Glitsch V-1 type valves.

After all the cleaning and security protocols were followed, an inspection was carried out on the inside of the atmospheric tower. The entrance to the tower was made at the height of plate 23, and then went up to the top of the tower and went down tray by tray. The most relevant findings of this activity are shown in Fig. 6.
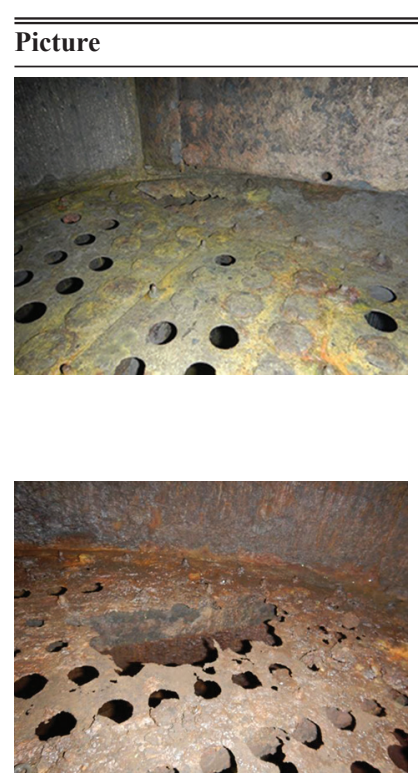

Comments

\section{TRAY 28-Monel}

The tray is in an advanced state of corrosion. It can be seen total perforation of the tray. The valve holes have lost dimension, which compromises the operation of the valves. The presence of salts adhered to the tower walls and tray can be observed. The presence of yellowish and whitish products stands out. The former is associated with sulfur products and the latter with ammonia salts

\section{Tray 24-SS410}

Note the areas with large holes caused by corrosion phenomena. This tray is not completely plugged but does not have associated valves. The valve ports have completely lost their dimensions

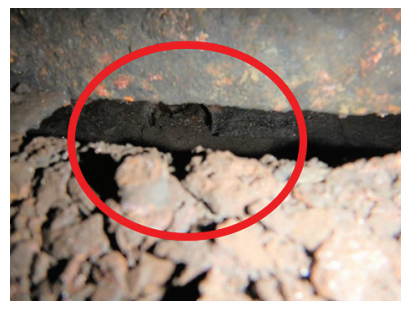

\section{Kerosene Nozzle}

This nozzle is partially plugged. The withdrawal tray has a large number of products and is deflected. There is no way this nozzle would allow kerosene removal. The red circle shows the uniqueness of the nozzle

Fig. 6. Some of the inspection findings inside the atmospheric tower.
The inspection allowed verifying that there is a serious phenomenon of plugging and corrosion in the tower. The main problem is in the quality of the feed supply to the unit; it is obvious that the water and sediment content and the concentration of salts are higher than the design of the unit has the capacity to process. For this reason, it was defined at this point that the main characteristic to study in this phenomenon is the content of salts in the feed crude.

Throughout 2020, the content of salts in feed crude oil is above 119 PTB, the month of March being the most critical with values as high as 355 PTB. These values are high if we consider that unit two does not have desalters, which are considered the first barrier to protect against corrosion and plugging.

Fig. 7 shows a graph with this year's trend. It is known that in previous years the salt content was much lower, even in other units of the refinery, which processes the same crude oil, work has been carried out even without a desalter, which is an indicator that the content of salts has varied greatly through time.

Apart from the precipitation temperature estimation exercises described above, there are other mechanisms to establish a relationship between salt content and corrosion and plugging in the internal part of the tower. One of them is the chemical analysis of the products found on the trays. Fig. 8 shows the results obtained in a sample extracted from the top section of the tower between trays 23 and 29. It can be seen that only $9 \%$ of the sample evaporated at $500^{\circ} \mathrm{C}$. The rest of the sample is soluble in water and in a solution acidified with $\mathrm{HCl}$, which is indicative that its composition is possibly salts and sediments, in addition to some corrosion products.

After the inspection was completed and the condition of the trays was verified, the question was raised as to whether the metallurgy of these components was correct. The tower has metallurgies set forth in the most recognized standards and recommended practices in the refining industry. Fig. 9 shows a simplified schematization of the overhead systems of the unit.

Three samples of Monel internals were analyzed using optical emission spectrometry technique. Sample number 1 corresponds to the valves, number 2 to the trays, and number

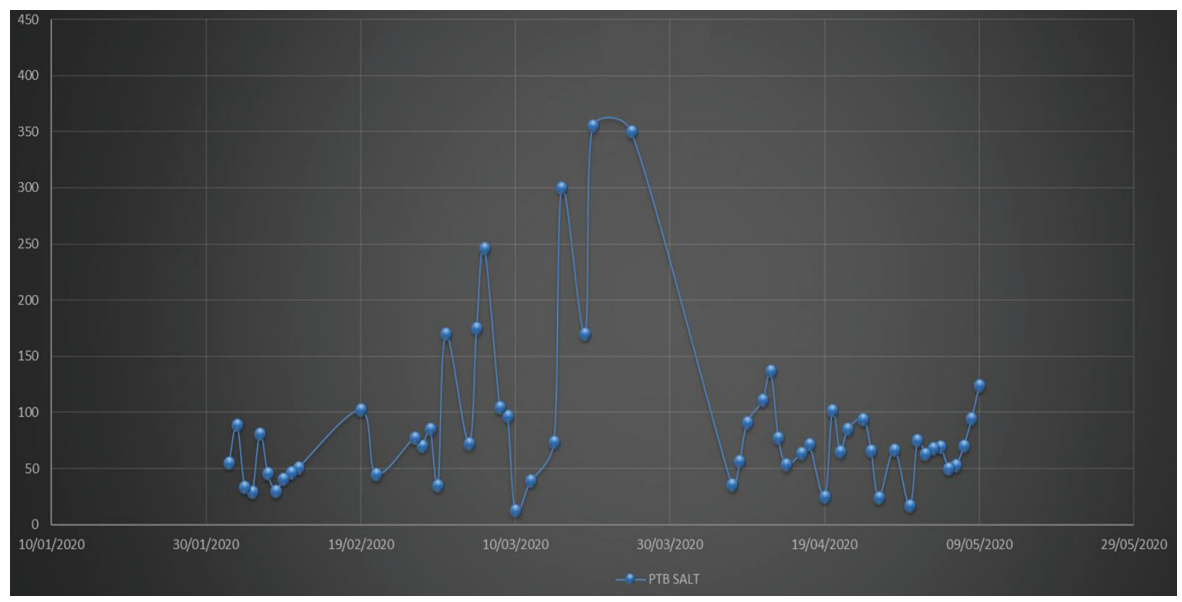

Fig. 7. Salts PTB trend in crude feed -2020. 
3 to the hardware. Taking into account the limitations of the test method, the results appear to be OK for valves and plates. The hardware turned out to be stainless steel. This represents a deviation generated during the installation of the internals.

The same procedure was repeated for the stainless-steel trays. The results area is presented in Tables II and III.

Nickel based alloys have been widely used in different applications in petroleum refining, due to its high corrosion resistant in different conditions (Groysman and Hiram, 1997). Alloy 400, Monel, is a precipitation alloy of nickel containing considerable amount of copper (approximately 30-33 wt \% copper) as a substantial element to provide solid solution strengthening. Furthermore, small amount of iron is added to improve the resistance of the alloy to cavitation and erosion in condenser tube application. It was reported by Groysman that, Monel 400, is susceptible to sulfide stress cracking when the surrounding environment contains sulfurous compounds such as hydrogen sulfide $\left(\mathrm{H}_{2} \mathrm{~S}\right)$, mercury salts, and hydrofluoric acid. The presence of oxidizing agents (oxygen, ferric, and cupric ions) will increase the corrosion rate, particularly for Alloy 400 and Alloy B-2.

Having evaluated all the morphological characteristics of the components degraded by corrosion, the chemical composition of the products found in the internal part of the

\begin{tabular}{cl}
\hline \hline Analysis steps & Description \\
\hline $1 \rightarrow$ & $5 \mathrm{~g}$ of sample in $500 \mathrm{ml}$ of $\mathrm{H}_{2} \mathrm{O}$ reduce the $\mathrm{pH}$ \\
& from 7 to 4.5 \\
& Ignition of $10 \mathrm{~g}$ at $500^{\circ} \mathrm{C}$ for $2 \mathrm{~h}$ and $30 \mathrm{~min}$. \\
& $9.6 \%$ wt. of organic compounds were lost \\
& After ignition, $1 \mathrm{~g}$ of sample was dissolved in \\
& $\begin{array}{l}\text { HCl. } 56.9 \% \text { wt. was lost, indicating possible } \\
\text { inorganic products }\end{array}$ \\
& After ignition, $1 \mathrm{~g}$ of sample was dissolved \\
& in $\mathrm{H}_{2} \mathrm{O} .31 \%$ wt. was lost, indicating possible \\
& salts \\
& Additional analysis: $\mathrm{Cl}^{-}=147 \mathrm{ppm}, \mathrm{SO}_{4}^{-2}=236$ \\
& ppm, $\mathrm{Ca}^{+2}=6200 \mathrm{ppm} . \mathrm{Na}^{+1}=108 \mathrm{ppm}$ \\
\hline \hline
\end{tabular}

Fig. 8. Lab results - sample taken from atmospheric tower internal trays. tower, as well as the metallurgy of the internal components, it can be concluded that there are combined corrosion mechanisms that affected the integrity of the atmospheric distillation tower and internals. Those mechanisms can be described as $\mathrm{NH}_{4} \mathrm{Cl}$ corrosion and $\mathrm{HCl}$ corrosion. These mechanisms are described in the literature as very aggressive and depend on the combination of a series of variables, which are observed in Fig. 10.

TABLE II

Chemical Composition of the Tower Internals in the Monel Section. 1-VaLVES, 2-Trays, 3-HardWARE

\begin{tabular}{lccc}
\hline \hline Element & Weight \%-1 & Weight \%-2 & Weight \%-3 \\
\hline $\mathrm{C}$ & 0.22 & 0.26 & 0.03 \\
$\mathrm{Si}$ & 0.95 & 1.56 & 0.45 \\
$\mathrm{P}$ & 0.01 & 0.01 & 0.03 \\
$\mathrm{~S}$ & 0.03 & 0.04 & 0.01 \\
$\mathrm{Cr}$ & 0.2 & 0.13 & 13.4 \\
$\mathrm{Mo}$ & 0.18 & 0.23 & 0.01 \\
$\mathrm{Ni}$ & $>52.2$ & $>52.2$ & 0.17 \\
$\mathrm{Al}$ & 0.39 & 0.4 & 0.01 \\
$\mathrm{Co}$ & 0.09 & 0.09 & 0.01 \\
$\mathrm{Cu}$ & $>9.72$ & $>9.72$ & 0.21 \\
$\mathrm{Nb}$ & 0.24 & 0.27 & 0.04 \\
$\mathrm{Ti}$ & 0.69 & 0.38 & 0.01 \\
$\mathrm{~V}$ & 0.9 & 0.9 & 0.05 \\
$\mathrm{~W}$ & 1.29 & 1.84 & 0.01 \\
$\mathrm{~Pb}$ & 0.07 & 0.07 & 0.01 \\
$\mathrm{Sn}$ & 0.04 & 0.04 & 0.01 \\
$\mathrm{Mg}$ & 0.09 & 0.11 & 0.01 \\
$\mathrm{As}$ & 0.03 & 0.03 & 0 \\
$\mathrm{Zr}$ & 0.21 & 0.02 & 0 \\
$\mathrm{Bi}$ & 0.04 & 0.04 & 0 \\
$\mathrm{Ca}$ & 0.02 & 0.01 & 0 \\
$\mathrm{Ce}$ & 0.04 & 0.04 & 0 \\
$\mathrm{Sb}$ & 0.29 & 0.28 & 0 \\
$\mathrm{Te}$ & 0.06 & 0.06 & 0 \\
$\mathrm{~B}$ & 0.01 & 0.01 & 0.05 \\
$\mathrm{Zn}$ & 0.05 & 0.03 & 0 \\
$\mathrm{La}$ & 0.03 & & 0 \\
\hline \hline
\end{tabular}

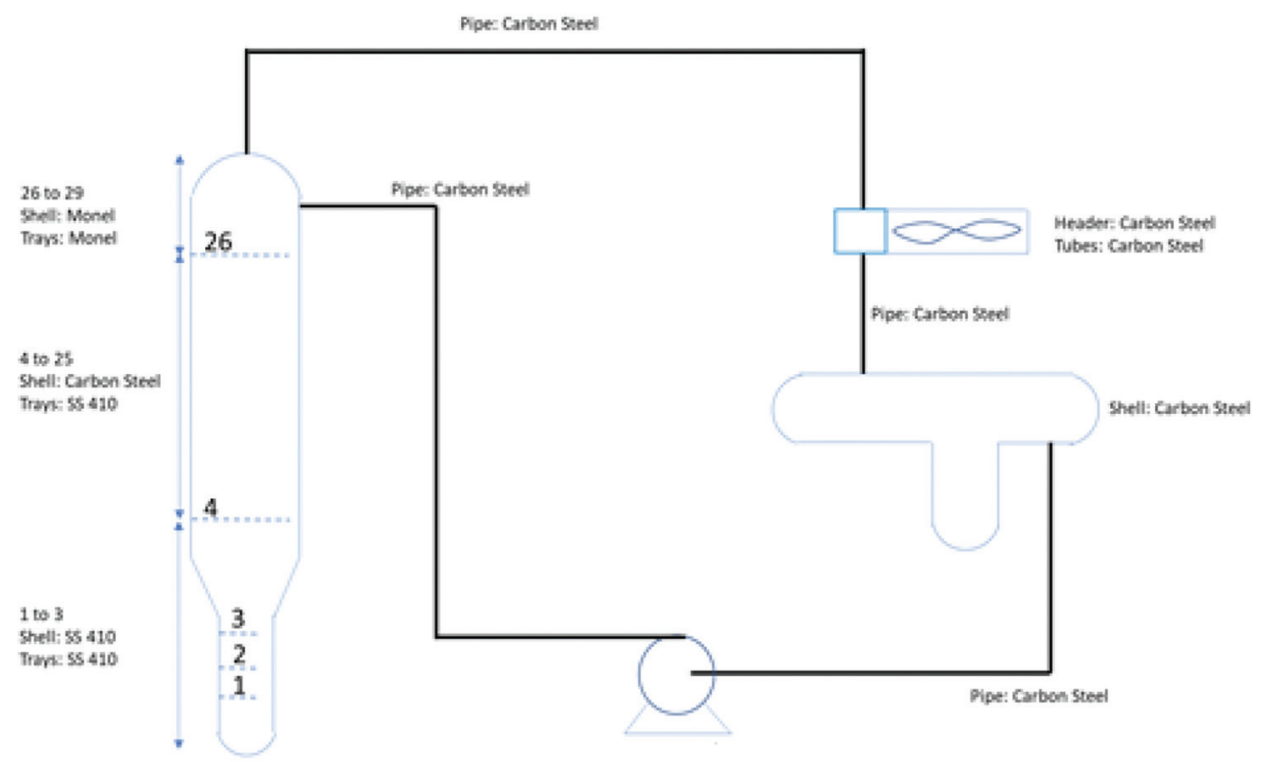

Fig. 9. Simplified schematization of the overheads systems in the units plus the entire tower metallurgy description. 


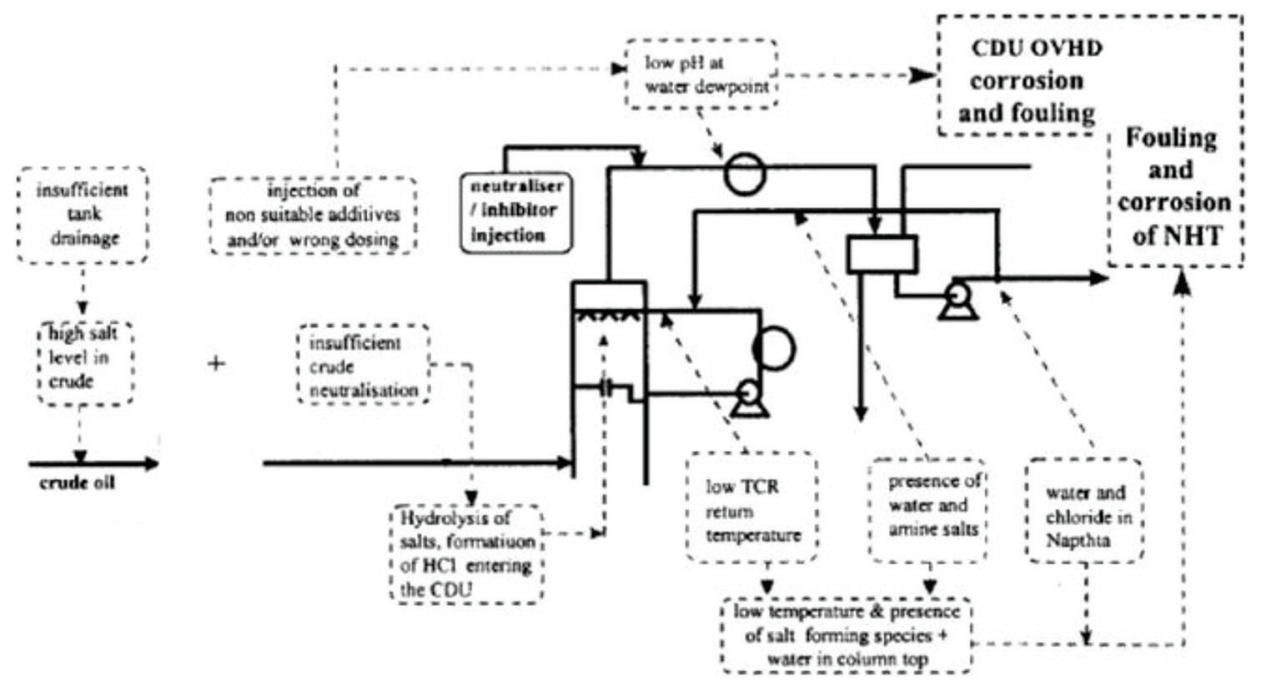

Fig. 10. Schematic of crude feed, desalter, atmospheric distillation unit, and overhead circuit along with common corrosion and fouling problems (Kapusta et al., 2001).

TABLE III

Chemical Composition of the Tower Internals in the Stainless-Steel SECTION. 1-Valves 2-Trays 3-HardWare

\begin{tabular}{|c|c|c|c|}
\hline Element & Weight $\%-1$ & Weight $\%-2$ & Weight $\%-3$ \\
\hline $\mathrm{C}$ & 0.18 & 0.22 & 0.04 \\
\hline $\mathrm{Mn}$ & 0.44 & 0.58 & 0.39 \\
\hline $\mathrm{Si}$ & 0.39 & 0.48 & 0.49 \\
\hline $\mathrm{S}$ & 0.01 & 0 & 0 \\
\hline $\mathrm{P}$ & 0.04 & 0.04 & 0.05 \\
\hline $\mathrm{Cr}$ & 12.46 & 13.91 & 13.19 \\
\hline $\mathrm{Ni}$ & 0.17 & 0.07 & 0.15 \\
\hline Mo & 0.02 & 0 & 0.01 \\
\hline $\mathrm{Cu}$ & 0.04 & 0 & 0.18 \\
\hline $\mathrm{V}$ & 0.05 & 0.03 & 0.05 \\
\hline $\mathrm{Ti}$ & 0 & 0 & 0 \\
\hline $\mathrm{Al}$ & 0 & 0 & 0 \\
\hline $\mathrm{Co}$ & 0.01 & 0 & 0.01 \\
\hline $\mathrm{Nb}$ & 0 & 0 & 0 \\
\hline $\mathrm{W}$ & 0.01 & 0.01 & 0.01 \\
\hline $\mathrm{Pb}$ & 0 & 0 & 0 \\
\hline $\mathrm{Sn}$ & 0.01 & 0 & 0.02 \\
\hline As & 0.05 & 0.03 & 0.03 \\
\hline $\mathrm{Ca}$ & 0 & 0 & 0 \\
\hline B & 0 & 0 & 0 \\
\hline $\mathrm{Fe}$ & 86.1 & 84.6 & 85.3 \\
\hline $\mathrm{Sb}$ & 0 & 0.01 & 0.01 \\
\hline
\end{tabular}

\section{CONCLUSIONS}

After having evaluated the operational context and the evidence of the inspections and analyzes carried out, it can be concluded that the degradation mechanism that has affected the internals of the atmospheric distillation tower under study was Corrosion by Ammonium Chloride $\left(\mathrm{NH}_{4} \mathrm{Cl}\right)$ in Combination with Corrosion by Hydrochloric Acid $(\mathrm{HCl})$. These mechanisms caused irremediable damage to the mechanical and metallurgical integrity of the tower's internals, making its operational performance impossible.

To remedy this problem and avoid a new occurrence, it is necessary to implement operational improvements, such as optimizing the primary treatment of crude oil in production facilities, reducing the water and sediment content to a maximum of $1 \%$, control the content of salts after desalters to a maximum of $30 \mathrm{ptb}$, define a new tankage strategy that improves dehydration, and, update the operating model of chemical treatments and washing water systems to adapt to the new conditions of the diets of the refinery.

\section{REFERENCES}

Braden, V., Petersen, P., Malpiedi, M., Bowerbank, L. and Gorman, J., 1998. Crude Unit Overhead Corrosion Control. CORROSION Conference, NACE International, Houston, USA, Paper No. 98585.

Chambers, B., Yap, K., Srinivasan, S. and Yunovich, M., 2011. Corrosion in Crude Distillation Unit Overhead Operations: A Comprehensive Review. CORROSION Conference, NACE International, Houston, USA, Paper No. 11360 .

Duggan, G. and Rechtien, R., 1998. Application of Ionic Equilibria Process Simulation for Atmospheric Distillation Overhead Systems. Corrosion/98, NACE International, Houston, TX, Paper No. 98586.

Eaton, P., Kaur, H. and Gray, M., 2009. Factors Affecting Salt Hydrolysis in Heavy Crude. Eurocorr/2009, Nice France, September, Paper No. 8295.

Fan, D., Fort, W., Shargay, C., Turner, J. and Messer, B., 2001. Design Considerations to Minimize Ammonium Chloride Corrosion in Hydrotreatment Reactions. Paper Presented at the CORROSION 2001, Houston, Texas, 01543.

Giesbrecht, V., Duggan, G. and Jackson, D., 2002. Effective Corrosion Control Techniques for Crude Unit Overheads. Corrosion/02, NACE International, Paper No. 02477.

Groysman, A. and Hiram, A., 1997. Corrosion Monitoring and Control in Refinery Process Units, Corrosion/97. NACE International, Houston, TX, Paper No. 97512.

Gutzeit, J., 2007. Controlling Crude Unit Overhead Corrosion Rules of Thumb for Better Crude Desalting. Corrosion/07, NACE International, Houston, TX, Paper No. 07567.

Kapusta, S., Ooms, A., Buijis, J., Fan, D. and Fort, W. $3^{\text {rd }}$., 2001. Systematic Approach to Controlling Fouling and Corrosion in Crude Unit Overheads and Hydrotreater Reactor Effluents. Corrosion/01, NACE International, Houston, 


\section{TX, Paper No. 01535.}

Lordo, S. and Eisenhawer, A., 2006. Sensitivity analysis for modeling overhead chloride salt deposition and corrosion issues. Journal of Physics: Conference Series, 1378, p.022089.

N.N., 2007. Corrosion Control in the Refining Industry Course Manual, Chapter 2: Crude Distillation and Desalting. NACE International, Houston, USA.

N.N., 2009. Crude Distillation Unit Distillation Tower Overhead System Corrosion, NACE International Publication 34109 (Task Group 342). NACE International, Houston, USA.

Rechtien, R. and Duggan, G., 2006. Identifying the Impacts of Amine
Contamination on Crude Units, CORROSION Conference. NACE International, Houston, USA, Paper No. 06851.

Saab, M., Dias, O.C. and Faqeer, F.M., 2005. Damage Mechanisms and Corrosion Control in a Crude Unit Overhead Line. Corrosion/05, NACE International, Houston, TX, Paper No. 05566.

Schempp, P., Preub, K. and Troeger, M., 2016. About the correlation between crude oil corrosiveness and results from corrosion monitoring in an oil refinery. Corrosion, 72, pp.843-855.

Thornthwaite, P. and Davies, J., 2016. Monitoring and simulation resolves overhead corrosion. $P T Q, 1$, pp.53-63. 